\title{
Online Individual Corrective Feedback: English Language Learners' Beliefs in Pronunciation Learning
}

\author{
Meilani $^{1 *}$, Didi Sukiyadi², Pupung Purnawarman ${ }^{3}$ \\ ${ }^{1,2,3}$ Department of English Language Education, Faculty of Language and Art Education, Universitas Pendidikan Indonesia, \\ Indonesia \\ *Corresponding author. Email: meilani@upi.edu
}

\begin{abstract}
Corrective feedback has been of great importance in foreign language acquisition since it helps improve oral production, especially when it is given individually to accommodate learners' various abilities and needs. In this pandemic context, the form of individual corrective feedback has shifted into online ones. Therefore, this study aimed to explore EFL learners' beliefs regarding online individual corrective feedback (hence OICF) in an online speaking club context. This is a case study implementing qualitative research through interviews with five selected participants. Observation and document analysis were also conducted as means of data collection. The data were analyzed through theme analysis. The finding shows that in terms of the OICF concept, the learners believe that OICF accommodates individuals' needs, helps them assess themselves, enriches their knowledge, and helps them build confidence. Concerning learning, they perceive that OICF increases their motivation, raises their language awareness, helps them build automaticity, and helps them make measurable progress. Regarding its practice, the learners believe that: 1) the practice helped them get connected; 2) the use of WhatsApp made them feel at ease; 3) their selfwillingness supported the practice; 4) reasonable challenges maintained their interest, and 5) the availability of visual aids as needed. The contents of OICF were in the form of three: word pronunciation, word stress, and intonation. The study implies that it is important for language instructors to provide individual corrective feedback both in online and offline learning contexts in addition to general feedback given to learners.
\end{abstract}

Keywords: learners' beliefs, online individual corrective feedback, pronunciation learning

\section{INTRODUCTION}

Many foreign language students are reluctant to speak English because they are concerned about their mastery of speaking skills. Anxiety about communicating in English is reported to be debilitating, affecting students' adaptability to the target environment and, as a result, hinder their ability to fulfil their educational goals [1]. Consequently, since anxiety has been shown to have a detrimental effect on some students' ability to speak English, teachers must be careful in helping to reduce second language anxiety [1]. There are different standards for speaking skills themselves. Vocabulary and expression, grammar, fluency, pronunciation and intonation, and interactive skill are the five criteria [2]. Because it is so observable, pronunciation is thought to be a great predictor that might impact students' confidence in speaking or be a source of concern. As a result, providing specific corrective feedback on pronunciation acquisition is one technique to assist learners in overcoming their nervousness.

Oral corrective feedback has long been valued in foreign language learning because it aids students in improving their oral performance [3]. Modified output can be manifested in the form of learner uptake, or learner responsiveness to teachers' remedial feedback given to learners' errors, in the context of teacher-learner interaction. Corrective feedback, for example, is a pedagogical method of providing students with adjusted input, which may result in modified output from the students. Long described the relationship between input, interaction, and acquisition as follows: (1) interactional modification makes input comprehensible, (2) comprehensible input promotes the acquisition, and (3) interactional modification promotes acquisition while discussing the Interaction Hypothesis [4, 5]. Corrective feedback and learner uptake, according to Long's description, could be regarded as beneficial processes for language development, particularly when corrective feedback and learner uptake are used as a source of interactional modification.

Many studies have expressed an interest in this issue, particularly in terms of teacher beliefs and perceptions of corrective feedback. However, in Indonesia, little study has been done on students' perceptions of online individual corrective feedback (later abbreviated as OICF) in EFL classes. On the subject of what students think about OICF, there is currently a lack of empirical evidence. It still needs further investigation. This study was carried out to fill this void. Therefore, the overall purpose of this study was to explore EFL learners' beliefs regarding individual corrective feedback in an online speaking club in Indonesia. More specifically, the research attempted to find out: 1) What are learners' beliefs about online individual corrective feedback (OICF) on pronunciation learning?; 2) How do learners 
describe the relationship between OICF to their pronunciation learning?; 3) How are learners' beliefs related to OICF practices?; and 4) What are contents of OICF on pronunciation learning the learners receive?

This research was intended to have theoretical and practical implications. In terms of theoretical significance, this study was expected to reinforce the latest theories used in this study and provide any necessary remarks. This research was expected to provide English teachers with some knowledge that would be beneficial as a reference for classroom teaching approaches. For fellow researchers, this study was expected to provide them with gaps and challenges to investigate further. For the researcher, it was hoped that this study would provide an insightful perspective on the importance of continuing to learn and reflect to improve English teaching skills.

\section{LITERATURE REVIEW}

The issue aroused in this study was seen from the perspective of five aspects constituting the problem. They are online learning, individual corrective feedback, pronunciation learning, the principle of language learning, and previous related studies. The literature used is described as follows.

\subsection{Online Learning}

"Online learning" refers to education that takes place over the internet. The term "e-learning" is widely used to describe it. On the other hand, online learning is merely one type of "distance learning" [6]. Internet-based courses, whether synchronous or asynchronous, each have its own set of benefits. Because the teacher can directly affect their response during the learning process, synchronous may be beneficial in terms of enhancing student engagement and motivation [7]. Because the time and location are both unrestricted, the asynchronous one offers more flexibility in the learning process [8]. In many ways, online courses are just as interesting and useful as their classroom counterparts. The main difference between online and traditional education is that online students can study from any location and at any time. In a classroom setting, both the teachers and the students must be in the same place at the same time. Everyone enrolling in an online course, on the other hand, has the freedom to work when and when it is most convenient for them [9].

There are advantages to online learning, but there are also disadvantages. The availability of online learning is a challenge for educators because the tools and opportunities for discovering students' preconceptions and cultural perspectives are frequently limited by bandwidth constraints, which limit users' view of body language and paralinguistic clues [10]. Its use is problematic in several investigations. Lack of Internet connectivity is one of the most common problems. Its use is problematic in several investigations.
Lack of Internet connection is one of the most common problems $[11,12,13]$.

\subsection{Individual Corrective Feedback}

Corrective feedback (CF) has been defined as a "complex phenomena with numerous purposes" as well as "responses to learner utterances including an error" [14, 15]. Therefore, individual corrective feedback (ICF) is responses to learner utterances given to a learner personally.

Good feedback practices consist of several criteria. They are: 1) assist in defining what constitutes good performance (goals, criteria, standards); 2) encourage students to put in "time and effort" on difficult learning assignments; 3 ) provide high-quality feedback that enables learners to self-correct; 4) provide opportunities for comments to be acted upon (to close any gap between current and desired performance); 5) ascertain that summative evaluation has a favourable impact on learning; 6) encourage discussion and conversation about learning (peer and teacher-student); 7) assist in the development of self-reflection and self-assessment in learning; 8) allow students to choose the assessment topic, method, criteria, weighting, and timing; 9) involve students in assessment policy and practice decision-making; 10) encourage the formation of learning communities and groups; 11) encourage positive self-esteem and motivational beliefs; and 12) provide teachers with information that can be used to assist them to shape their lessons [16].

\subsection{Pronunciation Learning}

Pronunciation is the act of making the sounds of a language that is not particularly helpful. The two parts of this subject that most people are concerned about are pronunciation standards and pronunciation learning. Brown stated that the majority of people who speak English are not always aware of the sounds they make or the sounds they hear. They concentrate solely on the meaning of the input and output: sounds serve as a conduit for information, not as a focus in and of themselves [17]. This is, without a doubt, the most efficient method of communication. In addition to the preceding reference, Indonesian students have difficulty learning English since they are accustomed to reading every letter in the Indonesian language [18]. Indeed, there are several distinctions between the English and Indonesian sound systems. Some English sounds do not exist in Indonesian, and those that do have the same articulation points in both languages have different articulation styles.

\subsection{Principle of Language Learning}

Various experts are talking about principles in ELT. Of them are Larsen-Freeman [20], Brown [21], Nation [23], and TESOL International Association [24]. Brown proposed twelve principles of ELT [21]. Six years later, the four strands of language learning were introduced by Nation at a 
conference in Australia [22]. The latest research crystalised the principles of ELT into six points namely knowing learners, creating conditions for language learning, designing high-quality lessons for language development, adapting lesson delivery as needed, monitoring and assessing student language development, as well as engaging and collaborating within a community of practice [23]. From those principles from three various sources, the last set of principles goes accordingly in this study because it enables the other sets of principles to combine in a more structured way. The third set of principles provides a general framework to follow. Later, in designing high-quality lessons, the four strands can be taken into account.

\subsection{Related Previous Studies}

Many studies have examined teachers' beliefs of corrective feedback. First, Lee studied the patterns of corrective feedback and learner repair found in advancedlevel adult ESL classrooms, as well as the preferences of both teachers and students for that input [24]. The student respondents preferred to receive explicit and immediate corrections in the middle of their dialogues and during teacher-student interactions. Instructors, on the other hand, were adamant that they should correct all of the students' flaws and blunders, despite acknowledging the value of teachers' corrective feedback and the efficacy of correcting students' errors immediately to improve their oral proficiency.

Junqueira and Kim evaluated the link between a novice and an experienced ESL teacher's previous training, teaching experience, CF beliefs, and behaviours [25]. Both teachers gave equivalent amounts of $\mathrm{CF}$ and had similar levels of student uptake and repair in their sessions, according to the data. The experienced teacher, on the other hand, generated more teacher-learner contacts and more forms of CF, which were more evenly distributed across language objectives. Teaching experience and training did not appear to have an impact on the teachers' ideas on CF inefficacy, but "apprenticeship of observation" appeared to have a greater impact on both instructors' belief systems.

In Roothoft's study, ten adult EFL teachers were observed and their claimed attitudes about oral feedback were compared [26]. Most of the teachers didn't seem to realize how much feedback they were giving or how many various forms of correction they were using. Even though all of the teachers thought that feedback was necessary, they were worried about interrupting pupils and causing negative emotional responses. This could explain why, in his data, recasts, a more implicit kind of feedback, were by far the most common way of correction. From the studies conducted, the majority focused on teachers' beliefs regarding CF. All studies were conducted in the context of face-to-face learning. For this reason, this study tried to examine learners' beliefs regarding ICF in an online context.

\section{METHODOLOGY}

This was a type of qualitative case study research that aimed to explore students' beliefs related to the concepts and practices of online individual corrective feedback (OICF). Due to space limitations, this study presents data related to students' beliefs about OICF focusing on interview data and student portfolios. This study was conducted in the context of an online learning community aimed to improve learners' English presentation skills. 53 postgraduate students from various study majors were members of this community which used various online learning platforms such as WA groups, Google Classroom, and Zoom Meeting Conferences.

Regarding pronunciation learning, the learners received a challenge to imitate the pronunciation of an expression once a day for six times a week called the Vocabulary Challenge. They also received an example of a pronunciation model of the targeted expression in an audio-graphic presentation. They listened to it then imitated the pronunciation along with the word stress and intonation and recorded it through the voice note feature on WhatsApp and sent it individually to an instructor. From the work they submitted, they received OICF from the instructor in the form of text or audio messages related to their performance when participating in the challenge. 36 challenges were given over two months. Five learners with the highest rate of participation were selected to be interviewed regarding their beliefs of OICF given when they took part in the vocabulary challenge.

\subsection{Data Collection}

This study employed observation, interviews, and learner portfolios as data collection methods. The observation was used to select learners to be interviewed. Interviews were conducted to explore learners' beliefs related to OICF, its relation to their learning, and its practices. Learner portfolios were used to find out the contents of the feedback given to learners.

The instruments used in this research included observation sheets, an interview guide, and a pronunciation analysis table. The observation sheet was in the form of a checklist table to monitor the learners' participation rate. The interview guide was used to conduct semi-structured interviews with the five selected learners. A pronunciation feedback analysis table was used to document the types of feedback provided by the instructor to the learners.

The data were collected through three stages. First, observations were made daily for thirty-six days to record the learners' participation in the vocabulary challenge. From these observations, five participants with the highest level of participation were selected to be interviewed to explore their beliefs related to OICF and its relation to their learning. Second, semi-structured interviews were carried out one by one through a zoom meeting conference. These interviews were recorded with the permission of the learners while 
maintaining the confidentiality of their identity. The interviews lasted about 15-25 minutes using the learners' native language, namely Indonesian. These interviews were later transcribed and translated into English. Thirdly, to find out the type of feedback that was provided, the learners' portfolio in the form of voice notes and feedback from the instructor in the form of voice notes and text messages were obtained from the instructor's documentation.

\subsection{Data Analysis}

Interview transcripts and learners' portfolio data were analysed using thematic analysis which consisted of six stages [27]. The first stage was familiarizing with the data or transcribing the verbal data and then reading and rereading the data. The second was generating initial codes. The third was searching for themes or focusing on the broader level of themes and involving sorting the different codes into potential themes. The fourth was reviewing themes. The fifth was defining and naming themes to capture the essence of what each theme was about and what aspect of the data each theme captured. The last was producing the report.

\section{FINDING AND DISCUSSION}

The findings are discussed in several points accordingly with the four research questions. The discussions are as follows.

\subsection{Learners' Belief about Online Individual Corrective Feedback (OICF) on Their Pronunciation Learning}

Overall, the learners stated that OICF is crucial in learning English pronunciation in particular and speaking in general. This is due to several things which are categorized as follows. Firstly, this type of feedback accommodates different individual needs. Unlike the general type of feedback that is given in forums for everyone, OICF is directly targeted at individuals so that learners feel that they are being helped to learn. The learners believe that individual corrective feedback is more accommodating to their needs than general feedback and this has been confirmed by the other four learners.

Second, the feedback corrected learners' mistakes and highlighted what they have done well so that they knew their strengths and weaknesses. The five learners stated that they felt being helped with the feedback given individually because they could know which were correct and which still needed to be improved. They often felt they were correct in pronouncing words and phrases until they received feedback from experts. For this reason, this feedback played its role as remedial actions for learners' mistakes and as reinforcement for things that are already correct. In other words, they know what weaknesses to be improved and what strengths need to be maintained. Knowing how far or how well their pronunciation performance is a support for their further progress.

Third, through the feedback, learners gained knowledge that they had often missed. The learner gets new knowledge, especially in terms of word stress. Word stress is an important part of the pronunciation of words because it will affect their meaning. This knowledge has certainly existed, however, through this OICF, learners know it more intensely so that it is more meaningful to them and more embedded in their memories. In addition, OICF helps learners to better absorb the vocabulary being studied.

This type of feedback also helps learners to build their self-confidence. This is because it was delivered directly to each person personally so they did not feel embarrassed when they made mistakes. When they had received feedback, they would correct their mistakes, so that what they performed in public was the correct one. This also further increased their confidence. In essence, learners believe that OICF has the concept that students receive feedback and act upon it. The instructor provides feedback following the performance of the learner. This OICF aims to provide remedial or reinforcement for their performance. Another side that learners underline is that while this type of feedback is very effective for them, it takes more time than general feedback. For this reason, the seriousness of the instructors in providing OICF is a good thing to spur their learning.

\subsection{Learners' Perception on the Relationship between OICF to Their Pronunciation Learning}

Learners' perceptions that emerged regarding the OICF relationship and their learning were categorized in 4 ways. They are increasing motivation, increasing awareness of language, building language automation, and making measurable progress. The feedback helps learners increase their learning motivation. The increase in enthusiasm for learning is also caused by the provision of individual feedback. This kept the learners motivated to always take the time to learn and follow the challenges given. In addition to increasing learning motivation, OICF also increases learners' language awareness. Because the learners felt they would be evaluated, they did not carelessly say the words or expressions given. This is an indicator that it has an impact on their language awareness. When they met words they were unsure of in pronunciation, they looked for references from various sources. In addition, they become more aware that English has many exceptions. Learners must pay attention to these exceptions and therefore, it will greatly affect their mastery of English.

Providing continuous feedback helps learners to improve their language automaticity. Sometimes learners make the same mistakes several times. Continuous feedback is provided to help them to see these mistakes so that these memories enter their long-term memory. After entering into 
long-term memory, their memory becomes stronger and the recall process becomes faster and language automation is formed. Furthermore, Feedback provided individually helps learners measure their learning progress more clearly. The OICF given by the instructor became the direction and measure of the progress of the learner. This is because learners can learn from their mistakes to make more meaningful progress. Thus, it hindered them to repeat the same mistake.

\subsection{Learners' Beliefs Related to OICF Practices}

The OICF carried out for thirty-five days delivered through the WhatsApp message and voice note feature gave a special impression to the learners. Learners believe that this kind of practice helps them to build rapport with the instructor and the learning environment. The sense of connection was created because the communication that was built was interpersonal between the learner and the instructor so that the learner can feel more intense learning monitoring. Because they feel monitored, students become more aware of their learning and feel more enthusiastic. The choice of WhatsApp as a medium for delivering the learners' work and feedback from instructors was seen as appropriate. The five interviewees state that WhatsApp is a user-friendly application with a more stable Internet network. Moreover, all learners owned it. This makes it easier for them to participate in the challenges given and access feedback whenever they want due to its high accessibility.

This OICF practice ran smoothly for the participants because of their high intrinsic motivation. They feel the need to participate in this activity because they still feel less skilled. Personal awareness of the importance of the pronunciation aspect in public speaking also supports the impact of this OICF. Learners' self-willingness is an important factor in the success of the practice. Thus, OICF has a more positive impact on responsive learners. Moreover, a reasonable level of difficulty is one of the factors that affect the resilience of learners' learning. The challenges that were still within the reach of the learner were gradually helping them to maintain their motivation in learning. The sense of success in something makes the learner feel even more successful. On the other hand, failing at something will usually reduce the motivation of the learner.

As previously mentioned, ICF accommodates the needs of individual learners. For this reason, it would be even better if the media used for the pronunciation model is not only audio but also a video so that students know how to pronounce a word or expression. There is always a tendency for different learning styles of learners, necessitating variations on the learning media used. For visual learners, visual aids help them in the learning process. Mainly related to pronunciation, visual aids provide illustrations of the sound coming out more clearly.

\subsection{Contents of OICF on Pronunciation Learning}

Most of the feedback received by learners includes three things, namely correction of word pronunciation, syllable stress, and intonation. This feedbacks were delivered via text messages or voice notes. Pronunciation errors were often experienced by the learners, especially in spelling that is almost the same or with certain exceptions. Examples of pronunciation errors were: the sound of $\theta$ and $ð$, the sound of $\mathrm{s} \int \mathrm{z} 3$, the sound of $\mathrm{f}, \mathrm{v}, \mathrm{w}$, the sound of $\mathrm{r}$, and the pronunciation of would, could, should. Word stress was also one of the contents of the feedback given. For words consisting of more than one syllable, at least one syllable should be suppressed. Sometimes the learners do not put stress on syllables that should be treated so. For example in the sound /spa'sif.Ik/, the learners often stress the first syllable, when it should be the second syllable. Pronunciation tips were also provided by the instructor in the feedback. The third feedback was intonation. An example of the feedback given was the intonation emphasized in the question. For interrogative sentences that require a yes/no answer, it should be rising intonation. Interrogative sentences related to $5 \mathrm{~W}+$ $1 \mathrm{H}$ have a falling intonation.

\section{CONCLUSION AND IMPLICATION}

This paper explored EFL learners' beliefs regarding online individual corrective feedback in an online speaking club context. The learners' beliefs discussed in this study strengthened the claim of Dorothy (2009) on good feedback criteria. This study implies that it is important for language instructors to provide individual corrective feedback both in online and offline learning contexts in addition to general feedback given in class. Therefore, they should allocate some time to have the greatest impact on learners' learning progress. For a big classroom setting, individual corrective feedback could be conducted once to thrice in the beginning, middle, or end overall meetings to keep learners being motivated. Especially, in pronunciation learning, individual corrective feedback plays an essential role in their learning improvement. This study also has several limitations. The participants being interviewed in this study only covered learners with high participation in the activity. Interviewing various types of participants would have given richer insight into the study. A questionnaire study could also be conducted to collect more learners' beliefs on online individual corrective feedback.

\section{ACKNOWLEDGMENTS}

I would like to express my sincere gratitude to MUHIBBA English Speaking Club (MESC) for the opportunity given to me to always learn and grow together especially for Muhammad Basir, S.Pd., Oktari Hendayanti, S.Pd., and Hega Nurazizah, S.Pd. who have provided me with solid support during the project. 


\section{REFERENCES}

[1] L. Woodrow, "Anxiety and speaking English as a second language," RELC J., vol. 37, no. 3, pp. 308-328, 2006, DOI: $10.1177 / 0033688206071315$.

[2] J. M. O'Malley and L. V. Pierce, Authentic Assessment for English Language Learners. Massachusetts: Addison-Wesley Publishing, 1996.

[3] M. F. Aranguiz and A. Q. Espinoza, "Estudios de lingüística inglesa aplicada," Estud. lingüística inglesa Apl., vol. 6, pp. 267-274, 2005, [Online]. Available: http://www.ncbi.nlm.nih.gov/entrez/query.fcgi?cmd=R etrieve $\& d b=$ PubMed\&dopt=Citation\&list_uids $=19893$ 492.

[4] M. Long, "A role for instruction in second language acquisition: Task-based language teaching," in Modelling and assessing second language acquisition, Clevedon, UK: Multilingual Matters, 1985, pp. 377393.

[5] H. Seliger and M. Long, Classroom-oriented research in second language acquisition. Rowley, MA: Newbury House, 1983.

[6] J. Stem, "Introduction to online teaching and learning," West LA College, 2020. http://www.wlac.edu/Online/documents/otl.pdf (accessed Dec. 14, 2020).

[7] S. Hrastinki, "Asynchronous and synchronous elearning," Educ. Q., vol. 31, pp. 51-55, 2008.

[8] F. Mayadas, "Asynchronous learning networks: a Sloan foundation perspective," J. Asynchronous Learn. Networks, vol. 1, pp. 1-16, 1997.

[9] University of Victoria, "How is online learning different from traditional learning?," Continuing Studies at UVIC, 2020. https://continuingstudies.uvic.ca/onlinelearning (accessed Dec. 14, 2020).

[10] T. Anderson, "Towards A Theory of Online Learning," Universite Saint Paul, 2020. https://ustpaul.ca/uploadfiles/DistanceEducation/TOWARDS_A_THEORY_O F_ONLINE_LEARNING.pdf (accessed Dec. 14, 2020).

[11] $\bar{M}$. Okmawati, "The use of Google Classroom during pandemic," J. English Lang. Teach., vol. 9, no. 2, pp. 438-443, 2020.

[12] A. B. Rinekso and A. B. Muslim, "Synchronous online discussion: teaching English in higher education amidst the Covid-19 pandemic," J. English Educ. Soc., vol. 5, no. 2, pp. 155-162, 2020.

[13] H. Mardiah, "The use of E-learning to teach English in the time of the Covid-19 pandemic.," English Teach. Linguist. J., vol. 1, no. 2, pp. 49-55, 2020.

[14] R. Ellis, "Researching the effects of form-focussed instruction on L2 acquisition," AILA Rev., vol. 19, pp. 18-41, 2006.

[15] C. Chaudron, Second language classrooms. New York: Cambridge University Press, 1988.

[16] D. Spiller, Assessment: Feedback to promote student learning. Hamilton: University of Waikato, 2009.

[17] L. Shockey, Sound Pattern of Spoken English. Oxford: Blackwell Publishing, 2003.

[18] S. Madya, Learning English Pronunciation Systematically. Yogyakarta: UNY Press, 2017.

[19] A. C. Gimson, An Introduction to the Pronunciation of
English. New York: St. Martin's Press, 1970.

[20] D. Larsen-Freeman, Techniques and Principles in Language Teaching. Oxford: Oxford University Press, 1986.

[21] H. D. Brown, Teaching by Principles. New York: Addison Wesley Longman, Inc, 2001.

[22] P. Nation, "The Four Strands," Innov. Lang. Learn. Teach., vol. 1, no. 1, pp. 2-13, 2007.

[23] TESOL International Association, "The 6 Principles for Exemplary Teaching of English Learners," The 6 Principles for Exemplary Teaching of English Learners, 2018. https://www.tesol.org/the-6-principles/the-6principles.

[24] E. J. Esther Lee, "Corrective feedback preferences and learner repair among advanced ESL students," System, vol. 41, no. 2, pp. 217-230, 2013, DOI: 10.1016/j.system.2013.01.022.

[25] L. Junqueira and Y. Kim, "Exploring the relationship between training, beliefs, and teachers' corrective feedback practices: A case study of a novice and an experienced ESL teacher," Can. Mod. Lang. Rev., vol. 69, no. 2, pp. 181-206, 2013, DOI: $10.3138 / \mathrm{cmlr} .1536$.

[26] H. Roothooft, "The relationship between adult EFL teachers' oral feedback practices and their beliefs," System, vol. 46, no. 1, pp. 65-79, 2014, DOI: 10.1016/j.system.2014.07.012.

[27] V. Braun and V. Clarke, "Using thematic analysis in psychology," Qual. Res. Psychol., vol. 3, no. 2, pp. 77101, 2006, DOI: 10.1191/1478088706qp063oa. 